\title{
Prediction of fatigue life of a continuous bridge girder based on vehicle induced stress history
}

\author{
V.G. Rao and S. Talukdar* \\ Department of Civil Engineering, Indian Institute of Technology, Guwahati-781039, India
}

Received 13 April 2003

Revised 4 June 2003

\begin{abstract}
The fatigue damage assessment of bridge components by conducting a full scale fatigue testing is often prohibitive. A need, therefore, exists to estimate the fatigue damage in bridge components by a simulation of bridge-vehicle interaction dynamics due to the action of the actual traffic. In the present paper, a systematic method has been outlined to find the fatigue damage in the continuous bridge girder based on stress range frequency histogram and fatigue strength parameters of the bridge materials. Vehicle induced time history of maximum flexural stresses has been obtained by Monte Carlo simulation process and utilized to develop the stress range frequency histogram taking into consideration of the annual traffic volume. The linear damage accumulation theory is then applied to calculate cumulative damage index and fatigue life of the bridge. Effect of the bridge span, pavement condition, increase of vehicle operating speed, weight and suspension characteristics on fatigue life of the bridge have been examined.
\end{abstract}

\section{Introduction}

Structural fatigue can be defined as the process of accumulation of damage due to application of time varying stress. It can be expected to occur whenever a structure is subjected to time varying loads and in many situations may govern the design. Each time a load cycle is applied, an incremental amount of damage occurs. This damage is cumulative in nature and accumulation continues till the failure occurs. If fatigue cracks are detected early, then repair may be possible. If not detected and properly repaired, the results may be disastrous failures. The bridges are one of the examples where similar situation may arise.

Fatigue behavior has become an important consideration in the design of bridges, and other engineering structures subjected to time varying loads. The importance of fatigue failure was first recognized in

\footnotetext{
${ }^{*}$ Corresponding author. E-mail: staluk@iitg.ernet.in.
}

metals. Bennantine et al. [1] described the theory of fatigue damage in metallic specimens. It is customary to study fatigue strength of the structural member based on constant amplitude fatigue test. The constant amplitude fatigue test result is usually represented in the form of $S-N$ curve ( $S$ : stress range, $N$ : number of cycles to failure). Miner [2] used $S-N$ curve approach to formulate a linear damage accumulation rule, which enables one to predict fatigue damage at each incremental stress range. Fatigue design criteria based on the $S-N$ curve approach in conjunction with linear damage hypothesis has been incorporated in American Association of State Highway and Transportation Official's (AASHTO) guide specification for fatigue of steel bridges [3], in British Standard Institution's code of practice for fatigue design of steel, concrete and composite bridges [4], in Indian Railway's bridge rules [5] and in Indian Road Congress (IRC) specification for road bridges of composite construction [6]. The drawback of these methods lies on the fact that the charts to be used in design calculations are based on constant 
amplitude fatigue test data, which does not reflect the stress developed in the members due to the dynamic interaction of vehicles with the bridge.

When structures or components are subjected to repeated applications of random forces, as with traffic loadings on the bridge, the number of cycles at which failure occurs are random variables. The complicated stress cycles induced by the variable amplitude load has been handled by statistical cycle counting method developed by Dowling [7]. Wirsching and Light [8] have conducted a study to develop an engineering model which was used for design purposes to predict metal fatigue under wide band random process. Lutes et al. [9] presented a stochastic fatigue damage theory to model uncertainty about stress time history. Numerical simulations were performed based on the existence of $S-N$ curves for constant amplitude fatigue. Lutes and Larson [10] have conducted study on the variable amplitude fatigue prediction characterizing the stress by power spectral density (PSD) function. Such an approach was found useful when one needs to predict fatigue life without knowing all details of loading and stress time history.

An alternative way for the fatigue assessment study of the structural members is based on the principles of fracture mechanics, which assumes an initial crack of a certain length and envisages its propagation until it has attained a critical length. Paris and Erdogen [11] developed a crack growth model which formed the basis of such study. From practice, it is generally known that a bridge with a fatigue crack can serve for a long time in normal conditions. Zhao et al. [12] and Ranganathan and Ravi [13] conducted studies on fatigue reliability of bridge components taking account of the phase of crack propagation.

Fatigue behaviour of steel and metal structures is more precisely known to date compared to plain, reinforced and prestressed concrete. The fatigue damage evaluation of steel railway bridges have been discussed by Fryba [14]. The observation from the field study conducted on steel railway bridges showed principal bridge elements like main girders endure a higher number stress cycles per year and also include stress cycles in higher stress range classes. The secondary bridge elements and orthotropic bridge deck endure lower number of stress cycles and stress ranges are lower. Illinois Department of Transportation [15] conducted a study of 15 steel bridges of various design throughout the state of Illinois. The stress range frequency histogram was analyzed to calculate damage incurred by the traffic passing over the bridge. The fraction of life consumed after 25 years traffic exposure in the cover-plated girder was found to be $6 \%$ to $10 \%$ of the service life of the bridge. With $10 \%$ increase of truck weight and $5 \%$ traffic growth, the fraction of life consumed in the same cover plated steel girder rises as high as 30\%. However, the stress magnitude in an element depends on its cross section and the distribution of load, as such the conclusions derived from these studies may not hold good for other steel railway bridges having different structural arrangement and traffic history.

The studies on the fatigue life of concrete bridges are very limited. Because of inherent variability of concrete, a probabilistic approach to predict the flexural strength of concrete was introduced by Oh [16]. The distribution of fatigue life of concrete under a given stress level is found from experimental results and presented as Weibull probability law. Perdikaris et al. [17] conducted model tests under static, fixed pulsating and moving wheel-load to study the effect of deck continuity and reinforcing pattern on ultimate and fatigue strength of concrete bridge deck slab supported on steel girders. Mohammadi et al. [18] presented the application of field data for condition assessment and prediction of service life of highway bridges composed of steel girders with reinforced concrete deck slabs. The field stress range data compiled for each bridge was used along with a probabilistic method to estimate fatigue life. Experimental studies conducted by Scalafli and Bruhwiler [19] have shown that fatigue loading causes progressive deterioration of bond between reinforcement and concrete. Failure was seen to normally occur due to rebar fatigue fracture. It was also observed that for slender flexural elements like slabs fatigue failure of concrete under normal compression forces is unlikely to occur and recommended that additional bending stresses for reinforcement should be considered.

Literature survey shows extensive works on the fatigue behaviour of structures made of metals based on which fatigue design criteria of steel bridges has been incorporated in the codes of practices. Fatigue tests results of concrete structures are relatively few and thus fatigue life estimation procedure for the concrete bridges are not well established. It is worth mentioning that fatigue life estimation depends on the underlying hypothesis to calculate damage. Besides, the complex interaction of the bridge with vehicle plays an important role in the prediction of the life. The fatigue provisions in the codes of practice for the design of bridges do not faithfully rely on the stresses induced in the bridge components due to dynamic interaction with 
the moving vehicles. Thus, the present study has been motivated towards the development of a procedure for the fatigue damage evaluation of bridges from vehicle induced stress history in a fatigue critical detail. A continuous bridge girder traversed by a rigid vehicle has been considered. The dynamic flexural stress induced at the critical location in the bridge has been obtained by Monte Carlo simulation as an intermediate step in the computation of fatigue life. The dynamic excitation to the bridge is assumed to be caused by the vehicle oscillation due to deck roughness. The deck roughness in the study has been considered as the variation of profile height of the bridge pavement with longitudinal distance. This has been treated as the realization of a homogeneous random process and described by PSD function. The statistical counting method has been applied to dynamic stress history at the critical locations to find number of cycles/year and corresponding stress range. The result of cycle counting has been presented in the form of histograms. For each stress range, the fraction of total damage has been calculated using Miner's rule and summation is carried out to cover all the stress blocks available in the histogram to find the cumulative damage index. Fatigue life of the bridge girder has been found from the cumulative damage index in the critical location. The effect of bridge span, vehicle speed, vehicle weight, suspension stiffness and deck roughness on the fatigue life of the bridge has been examined

\section{Fatigue strength}

Both the material properties and the dynamic load process are important for fatigue evaluation. The simplest of all fatigue load processes is periodic load, which is defined as constant amplitude load cycle. Empirical data from such constant amplitude tests form the basis for the prediction of fatigue life under complicated time history. Constant fatigue behavior is determined experimentally from tests in which a load or deflection is controlled and varied in simple periodic manner until failure. In this situation, fatigue failure is usually found to depend significantly on only two characteristics of time histories. These two characteristics can be taken as minimum and maximum values of stresses during the cycle shown in Fig. 1. An alternative formulation uses the mean stress value, defined as the average of the minimum and maximum stresses, and stress range value defined as the difference of the maximum and minimum stress. The stress range effect is usually found to be considerably more important than mean stress. The result of a constant amplitude fatigue test is often described by stress range $S r$, and number of cycles to failure denoted by $N_{f}$. A typical experimental investigation of constant amplitude fatigue for a specimen of given configuration and material involves a large number of tests. The test results are usually presented in the form of $S-N$ curve with the stress range on the ordinate and the number of cycles on the abscissa as shown in Fig. 2.

The experimental data commonly show that a large portion of $S-N$ curve is well approximated by an equation of the form

$$
N_{f}=K S_{r}^{-m}
$$

in which $K$ and $m$ are the positive material constants whose values depend on both materials and geometry of the specimen. The constants $K$ and $m$ for different metals and their alloys have been compiled by American Society of Metals [20] which are readily applicable for the fatigue analysis of metallic specimen. The Eq. (1) is very often represented in linear form as

$$
y=c+\alpha x
$$

where $y=\log \left(N_{f}\right), c=\log (k)$ and $\alpha=-m, x=$ $\log \left(S_{r}\right)$.

\section{Theory of damage accumulation}

A vehicle passing over a bridge induces dynamic load as a result of the vehicle oscillation. These load time histories are much complicated from periodic loadings used in laboratory fatigue testing because of the random nature of the vehicle excitation caused by pavement roughness. This load-time history is generally dominated by one large cycle equal to the peak live load produced by the vehicle. Dynamic effects generate additional small cycles superimposed on the large cycle. To assess the fatigue damage caused by the passage of vehicle, it is necessary to account for both the large dominant cycle and the small-superimposed cycles. The basic problem of fatigue analysis is to use appropriately the $S$ - $N$ curve data from the periodic tests to predict fatigue life of an element or assembly, which is subjected to a service load having a complicated time history. In case of random load history, the Eq. (1) can not be used without additional information. The theory proposed by Miner [2] has been used based on the fact that the random time history can be considered to be a superimposition of harmonic waves with different 


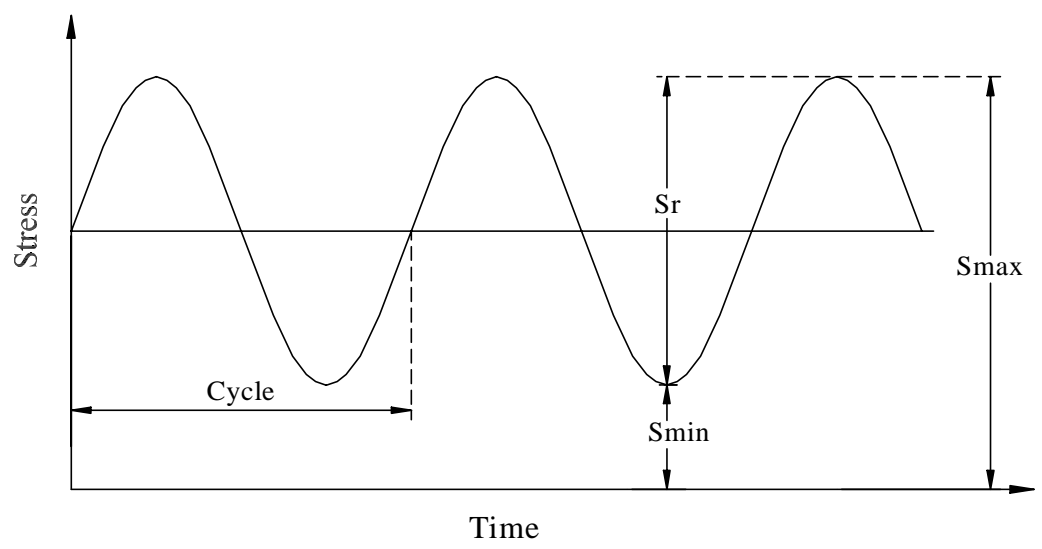

Fig. 1. A typical stress history for the constant amplitude loading.

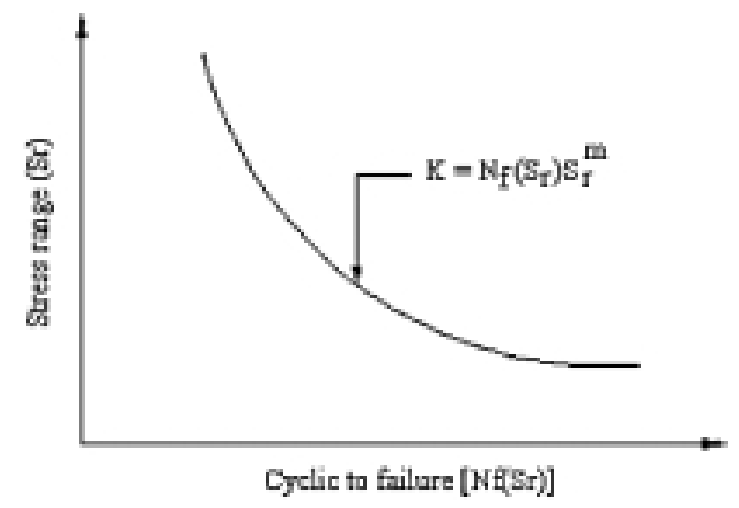

Fig. 2. A typical $S$ - $N$ Curve for constant amplitude test results.

amplitude and different frequencies. Thus the fraction of damage accumulated due to application of $n_{j}$ cycles at a stress amplitude $\xi_{0}$ is

$$
\Delta D_{j}=\frac{n_{j}}{N_{f j}}\left(n_{j}<N_{f j}\right)
$$

where $N_{f j}$ is the number of cycles to fatigue failures at the stress range $S_{r}$.

The Eq. (3) is presumed to apply to general loading conditions if the effect of loading can be looked upon as the combination of several simple cyclic loadings. The problem is to decompose a complicated time history into simple cycles, to count those cycles and to determine an incremental damage $D_{j}$ for each cycle. In the present study, the rain flow cycle counting method proposed by Dowling [7] has been used.

\subsection{Rainflow counting method}

The rainflow method of cycle counting is widely used in practice. This method obtained its name from an idea that water is flowing along a pagoda-shaped roof. The basic idea behind any stress cycle identification scheme is to consider the segment of a stress time history $S_{r}(x, t)$ between any two subsequent local extrema (from peak to a valley or from valley to a peak) to be a half cycle. The evaluation of random processes with reference to the fatigue of structures is based on the stress-time history. The fundamental assumption of the rainflow counting method is that fatigue damage due to small induced stress cycles may be added to the fatigue damage due to large stress cycles. The algorithm for "Rainflow Counting" is described below with help of schematic diagram of stress cycle in Fig. 3.

(1) The local peaks $A(0), A(1), \ldots, A(k)$ are read from the stress time history and digitized.

(2) The set of local peaks obtained is decomposed into half-cycles and cycles.

(3) The condition for a cycle counting is defined by the relations

$$
\begin{aligned}
A(i-1) & \leqslant A(i+1)<A(i) \\
& \leqslant A(i+2)
\end{aligned}
$$

or

$$
\begin{aligned}
A(i-1) & \geqslant A(i+1)>A(i) \\
& \geqslant A(i+2)
\end{aligned}
$$

(3a) The computation proceeds from the lowest $i=1$ to the highest $i=k-2$. If the conditions (4) or (5) have been complied with, one cycle $=$ two half cycles with the stress range

$$
S_{r}=|A(i)-A(i+1)|
$$




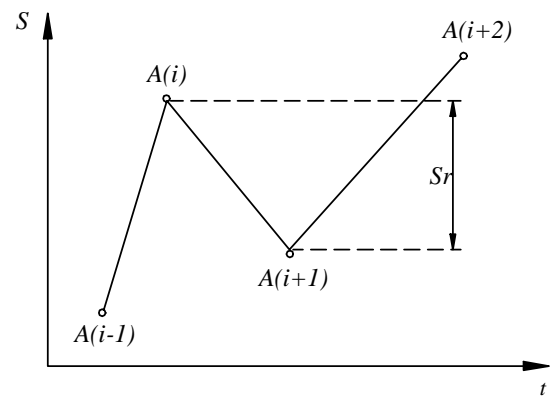

(a) Rising

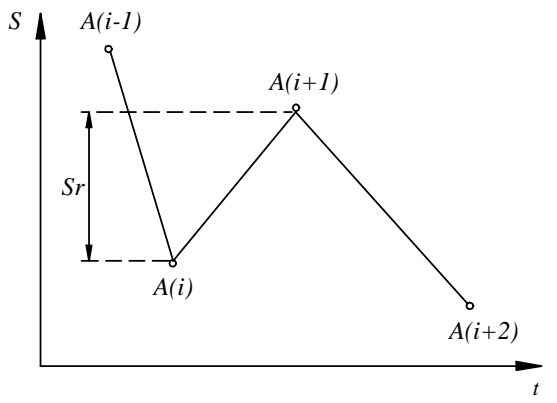

(b) Decaying part of the time history

Fig. 3. Two basic cases of complete cycle counting in the Rainflow method.

(3b) The peaks $A(i)$ and $A(i+1)$ are eliminated from the sequence of extremes and sequence is renumbered.

(3c) The procedure according to (3a) and (3b) are repeated until at least one cycle has remained from the remaining sequence.

(4) If the decomposition into cycle has been completed, the stress ranges (i.e. absolute values of differences of adjoining extremes) in the remaining sequence are called half-cycles.

(5) The cycles and the remaining half-cycles of equal magnitude are added in the course of the calculations; the result is a table of stress range frequencies, usually represented in the form of a frequency histogram and called stress range spectrum. The cycles counted for each time history is extrapolated by the ratio of the annual and measured traffic loads yielding the total number of stress cycles per year for a bridge element.

\section{Bridge-vehicle interaction model}

To apply the concept of fatigue damage accumulation in bridge, the vehicle-induced stress at the critical section of a multi span girder bridge has been considered in the present study. The multi-span highway bridge is modeled as a continuous beam with unyielding supports. The mass, stiffness and damping properties are assumed uniform along the beam. Vehicle has been modeled as a rigid beam connected by front and rear suspension. The mass of the vehicle body is lumped at the centroid of the beam and known as sprung mass. The mass of the wheels, tires and part of the suspension system is referred as the unsprung mass. As the front and rear axles are subjected to different random input of deck profile, vehicle is subjected to pitching in addi-

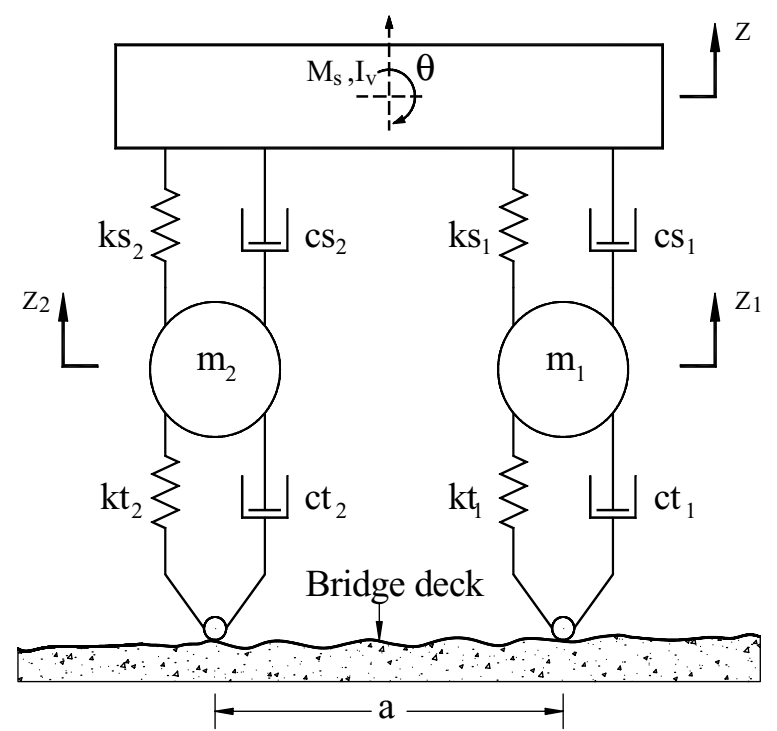

Fig. 4. An idealized vehicle model.

tion to bounce. The bridge-vehicle interaction model is shown in Figs 4 and 5. The dynamic force transmitted on the bridge is the result of vehicle oscillation caused by the pavement roughness.

\subsection{Deck roughness}

The source of excitation to moving vehicle is the deck roughness which in turn induce time varying force on the bridge. In the present study, the road roughness has been considered to be the realization of stationary random process described by the PSD function. Hwang and Nowak [21] suggested the following form of PSD of deck roughness as the dynamic input to the moving vehicles.

$$
S_{r}\left(\Omega_{k}\right)= \begin{cases}\alpha_{s} \Omega_{k}^{-\beta_{r}}, & \text { for } \Omega_{l}<\Omega_{k}<\Omega_{u} \\ 0 & \text { else where }\end{cases}
$$




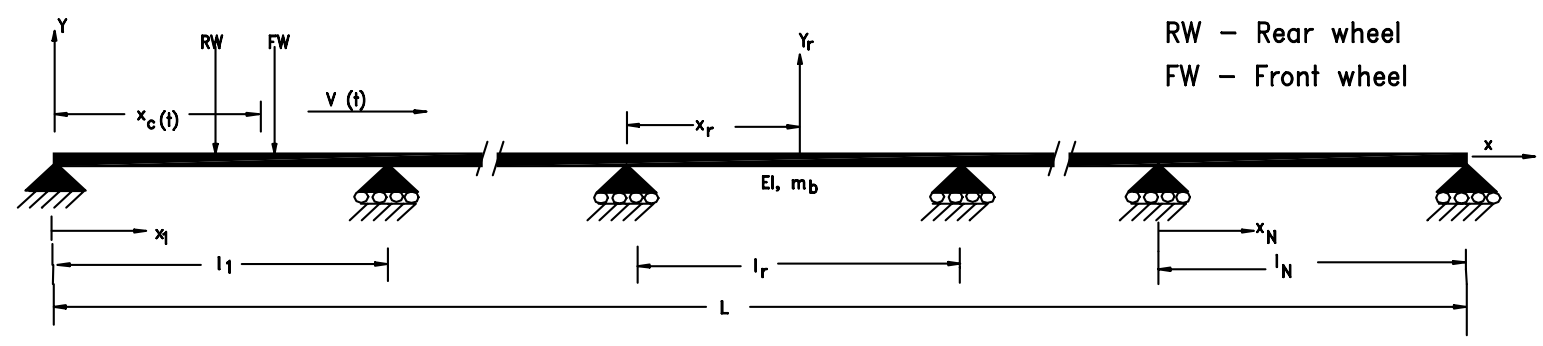

Fig. 5. A model of multispan girder bridge.

in which $S_{r}\left(\Omega_{k}\right)$ is the PSD function, $\Omega_{k}$ is the spatial frequency of the road surface roughness. $\Omega_{l}$ and $\Omega_{u}$ is the lower limit and upper limit of the spatial frequency. The parameter $\alpha_{s}$ is the spectral roughness coefficient in $\mathrm{m}^{2} /(\mathrm{m} /$ cycle $)$ and $\beta_{r}$ is the spectral exponent. The temporal frequency $\omega(\mathrm{rad} / \mathrm{sec})$ can be related to spatial frequency of the surface roughness by the following equation

$$
\omega=\Omega V
$$

in which the $V$ is the vehicle forward velocity. The road surface condition may be classified in to five classes such as very good, good, average, poor and very poor according to ISO specification in terms of the roughness coefficients.

\subsection{Equation of motions}

The equation of heave and pitch motion of the sprung mass can be written as:

$$
\begin{aligned}
& M_{s} \ddot{Z}+c s_{1}\left(\dot{Z}+l_{a 1} \dot{\theta}-\dot{Z}_{1}\right) \\
& +c s_{2}\left(\dot{Z}-l_{a 2} \dot{\theta}-\dot{Z}_{2}\right)+k s_{1}\left(Z+l_{a 1} \theta-Z_{1}\right) \\
& +k s_{2}\left(Z-l_{a 2} \theta-Z_{2}\right)=0 \\
& I_{v} \ddot{\theta}+c s_{1}\left(\dot{Z}+l_{a 1} \dot{\theta}-\dot{Z}_{1}\right) l_{1 a} \\
& -c s_{2}\left(\dot{Z}-l_{a 2} \dot{\theta}-\dot{Z}_{2}\right) l_{a 2} \\
& +k s_{1}\left(Z+l_{a 1} \theta-Z_{1}\right) l_{a 1} \\
& -k s_{2}\left(Z-l_{a 2} \theta-Z_{2}\right) l_{a 2}=0
\end{aligned}
$$
by

The front and rear wheel bounce can be represented

$$
\begin{aligned}
& m_{1} \ddot{Z}_{1}+c s_{1}\left(\dot{Z}_{1}-l_{a 1} \dot{\theta}-\dot{Z}\right) \\
& +c t_{1}\left[\dot{Z}_{1}-\dot{h}\left(x_{1}\right)-\dot{y}_{r}\left(x_{1}, t\right)\right] \\
& +k s_{1}\left(Z_{1}-l_{a 1} \theta-Z\right) \\
& +k t_{1}\left[Z_{1}-h\left(x_{1}\right)-y_{r}\left(x_{1}, t\right)\right]=0
\end{aligned}
$$

$$
\begin{aligned}
& m_{2} \ddot{Z}_{2}+c s_{2}\left(\dot{Z}_{1}+l_{a 2} \dot{\theta}-\dot{Z}\right) \\
& +c t_{2}\left[\dot{Z}_{1}-\dot{h}\left(x_{2}\right)-\dot{y}_{r}\left(x_{2}, t\right)\right] \\
& +k s_{2}\left(Z_{2}+l_{a 2} \theta-Z\right) \\
& +k t_{2}\left[Z-h\left(x_{2}\right)-y_{r}\left(x_{2}, t\right)\right]=0
\end{aligned}
$$

where $M_{s}$ is the sprung mass of the vehicle; $m_{1}$ and $m_{2}$ are the front and rear unsprung masses respectively; $k_{s 1}$ and $k_{s 2}$ are the front and rear suspension stiffness respectively; $c_{s 1}$ and $c_{s 2}$ are damping constants of front and rear suspension respectively; $k_{t 1}$ and $k_{t 2}$ are the stiffness of the front and rear tyres respectively; $c_{t 1}$ and $c_{t 2}$ are the damping of the front and rear tyres respectively; $I v$ is the moment of inertia of the vehicle body; $Z, Z_{1}$ and $Z_{2}$ are the vertical displacements of the sprung mass, front and rear unsprung masses respectively; $\theta$ is the pitch rotation of the vehicle; $l_{a 1}$ and $l_{a 2}$ are the distances of the front and rear unsprung mass from the vehicle c.g; $y_{r}\left(x_{1}, t\right)$ and $y_{r}\left(x_{2}, t\right)$ are the respective bridge displacements under front and rear wheels at arbitrary time $t ; h\left(x_{1}\right)$ and $h\left(x_{2}\right)$ represents the random input of deck profile under the front and rear wheels respectively. $\dot{h}\left(x_{1}\right)$ and $\dot{h}\left(x_{2}\right)$ are the time derivatives of the random input of deck profile, at location $x_{1}$ and $x_{2}$. All vertical displacements are assumed positive. The pitch rotation of the vehicle body is assumed positive clockwise.

The governing differential equation of motion of the bridge can be expressed as

$$
E I \frac{\partial^{4} y_{r}}{\partial x_{r}^{4}}+c \frac{\partial y_{r}}{\partial t}+m_{b} \frac{\partial^{2} y_{r}}{\partial t^{2}}=f\left(x_{r}, t\right)
$$

$E I, m_{b}$ and $c$ denotes the flexural rigidity, mass and viscous damping per unit length respectively whereas the imposed distributed load on the bridge is denoted by $f\left(x_{r}, t\right)$. This is given by

$$
\begin{aligned}
f\left(x_{r}, t\right)= & \left\{c t_{1}\left[\dot{Z}_{1}-\dot{h}\left(x_{1}\right)-\dot{y}\left(x_{1}, t\right)\right]\right. \\
& \left.+k t_{1}\left[Z_{1}-h\left(x_{1}\right)-y\left(x_{1}, t\right)\right]\right\} \\
& \delta\left(x-x_{1}\right)
\end{aligned}
$$




$$
\begin{aligned}
& +\left\{c t_{2}\left[\dot{Z}_{2}-\dot{h}\left(x_{2}\right)-\dot{y}\left(x_{2}, t\right)\right]\right. \\
& \left.+k t_{2}\left[Z_{2}-h\left(x_{2}\right)-y\left(x_{2}, t\right)\right]\right\} \\
& \delta\left(x-x_{2}\right)
\end{aligned}
$$

in which $\delta$ is the Dirac delta function.

Using mode superposition principle [22], the transverse displacement of the bridge can be expressed as

$$
y_{r}\left(x_{r}, t\right)=\sum_{n=1}^{N_{b}} \phi_{n r}(x) \eta_{t}(t)
$$

in which $\phi_{n r}(x)$ is $n$th bending mode shape function of the $r$ th span; $\eta_{t}(x)$ is the corresponding generalized time-dependent normal co-ordinate. The expression for the mode shape function corresponding to an undamped natural frequency can be obtained by using the following homogeneous solution of the Eq. (13).

$$
\begin{aligned}
\phi_{n r}(x)= & A_{n r} \sin \beta_{n r} x_{r}+B_{n r} \cos \beta_{n r} x_{r} \\
& +C_{n r} \sinh \beta_{n r} x_{r}+D_{n r} \cosh \beta_{n r} x_{r}
\end{aligned}
$$

where $A_{n r}, B_{n r}, C_{n r}$ and $D_{n r}$ are the integration constants, $\phi_{n r}(x)$ is eigen function of the $n$th mode of the $r$ th span. The $\beta_{n r}$ denotes frequency parameter per unit length in the $n$th mode which is given by

$$
\beta_{n r}^{4}=\frac{m \omega_{n}^{2}}{E I}
$$

in which $\omega_{n}$ is the natural frequency of the beam $(\mathrm{rad} / \mathrm{sec})$. The following boundary conditions of continuous beam need to be applied in Eq. (16)

$$
\begin{aligned}
& y_{r}\left(x_{r}=l_{r}, t\right)=0 \\
& y_{(r+1)}\left(x_{r+1}=l_{r}, t\right)=0 \\
& \frac{\partial y_{r}}{\partial x_{r}}\left(x_{r}=l_{r}, t\right)=\frac{\partial y_{(r+1)}}{\partial x_{(r+1)}}\left(x_{r+1}=0, t\right) \\
& \frac{\partial^{2} y_{r}}{\partial x_{r}^{2}}\left(x_{r}=l_{r}, t\right)=\frac{\partial^{2} y_{(r+1)}}{\partial x_{(r+1)}^{2}}\left(x_{r+1}=0, t\right) \\
& r=1,2,3, \ldots, N
\end{aligned}
$$

Upon substitution of boundary conditions given by Eq. (18) in Eq. (16), a set of homogeneous equations can be found in the matrix form as

$$
\left[V\left(\beta_{n r}\right)\right]\{W\}=\{0\}
$$

The non-trivial solution of the Eq. (19) necessitates that the determinant of the matrix $\left[V\left(\beta_{n r}\right)\right]$ should be equal to zero. After expanding the determinant the characteristic polynomial can be solved to find the frequency roots which when substituted in Eq. (16) yields the vector $\{W\}$ and hence the mode shapes. The expression of mode shape functions obtained by symbolic computation with the software MAPPLE are given in the Appendix-II.

Upon obtaining mode shape function and natural frequencies, Eq. (15) is substituted in Eq. (13), both sides are multiplied by $\phi_{n r}(x)$ and finally integrated in the domain of the beam making use of the orthogonality conditions. The set of operations results in the discretization of the partial differential Eq. (13) in to the uncoupled ordinary differential equations in the normal coordinates as

$$
\begin{aligned}
& \ddot{\eta}_{k}(t)+2 \zeta_{k} \omega_{b k} \dot{\eta}_{k}(t)+\omega_{b k}^{2} \eta_{k}(t)=Q_{k} \\
& \left(k=1,2, \ldots, n_{b}\right)
\end{aligned}
$$

in which $\zeta_{k}$ is the modal damping ratio. The right hand side of the Eq. (20) represents the generalized force due to the vehicle interaction at two contact points which can be expressed as

$$
\begin{aligned}
& Q_{k}= \\
& \left\{C_{1}\left[\dot{Z}_{1}-\dot{h}\left(x_{1}\right)-\sum_{i=1}^{n_{b}} W_{k}\left(x_{1}\right) \dot{\eta}_{k}(t)\right]\right. \\
& \left.+K_{1}\left[Z_{1}-h\left(x_{1}\right)-\sum_{i=1}^{n_{b}} W_{k}\left(x_{1}\right) \eta_{k}(t)\right]\right\} \\
& W_{k}\left(x_{1}\right) \\
& +\left\{C_{2}\left[\dot{Z}_{2}-\dot{h}\left(x_{2}\right)-\sum_{i=1}^{n_{b}} W_{k}\left(x_{2}\right) \dot{\eta}_{k}(t)\right]\right. \\
& \left.+K_{2}\left[Z_{2}-h\left(x_{2}\right)-y\left(x_{2}, t\right)\right]\right\} W_{k}\left(x_{2}\right)
\end{aligned}
$$

The bridge-vehicle dynamic Eqs (9)-(12) and (16) can now be arranged in matrix form as

$$
\begin{aligned}
& {[M]\{\ddot{U}(t)\}+[C]\{\dot{U}(t)\}+[K]\{U(t)\}} \\
& =\{F(t)\}
\end{aligned}
$$

where $[M],[C]$ and $[K]$ are the system mass, damping and stiffness matrices respectively. $\{F(t)\}$ is the force vector and $\{U(t)\}$ is the response vector. The vector $\{U(t)\}$ contains the generalized coordinates $Z, \theta, Z_{1}, Z_{2}, \eta_{1}, \eta_{2}, \eta_{3}, \ldots, \eta_{n}$. The size of system matrices with $n_{b}$ significant bending modes of the bridge will be $4+n_{b}$. The force vector $\{Q(t)\}$ and its derivative process is the function of deck roughness. 


\section{Stress time history}

The stress time history at any specific location of the bridge can be obtained by solving the dynamic equilibrium Eq. (22), which is required to estimate the fatigue life of the bridge component according to the proposed theory. Since the dynamic loading on the bridge is random, Monte Carlo simulation technique is adopted to find the average stresses induced by moving vehicles. The random pavement profile is the source of the dynamic excitation, which has to be fed as input to the system model. A sample of the process has been simulated from the PSD function using the following expression given by Hwang and Nowak [21]

$$
h(x)=\sum_{k=1}^{N} \alpha_{k} \cos \left(2 \pi \Omega_{k} x+\varphi_{k}\right)
$$

where $\alpha_{k}$ is the amplitude of the cosine wave, $\Omega_{k}$ is the frequency in the interval $\left[\Omega_{l}, \Omega_{u}\right]$ in which power spectral density function is defined, $\varphi_{k}$ is the random phase angle with uniform probability distribution in the interval $[0,2 \pi], x$ is the global coordinate measured from the left end of the bridge and $\mathrm{N}$ is the total number of terms used to built up the road surface roughness.

The parameters $\Omega_{k}$ is

$$
\alpha_{k}^{2}=4 S_{r}\left(\Omega_{k}\right) \Delta \Omega
$$

where $\Delta \Omega$ is the sampling interval. $S_{r}\left(\Omega_{k}\right)$ is the power spectral density function (in $\mathrm{m}^{3} / \mathrm{rad}$ ), $\Omega_{l}$ and $\Omega_{u}$ are the lower and upper cut-off spatial frequencies (in $\mathrm{rad} / \mathrm{m}$ ), respectively. Upon generating a sample of force vector $\{Q(t)\}$ related to surface roughness and its derivative process, the response $\{U(t)\}$ is obtained by Newmark Beta integration scheme. The algorithm for the computer implementation has been described by Bathe and Wilson [23]. The step-by-step integration of the system equations is repeated with ' $n$ ' number of input samples to yield corresponding samples of the response process. Each of the samples of the ensemble of the response is then post processed for cycle identification, developing stress frequency histogram, computing the damage accumulation and finally to find the fatigue life.

\section{Fatigue life estimation}

The effect of variable-amplitude loading (i.e., random load or irregular) on fatigue performance is normally accounted for with cumulative damage rules. The linear damage accumulation hypothesis is widely used in the design codes. Extending Miner's rule, the cumulative damage accumulation under variableamplitude loading for a particular sample of stress history is given by

$$
D_{I}=\sum_{j=1}^{k_{b}} \Delta D_{j}=\sum_{j=1}^{k_{b}} \frac{n_{j}}{N_{j}}
$$

in which $D_{I}$ is the cumulative damage index, $D_{j}$ is the incremental damage, $n_{j}$ is the number of stress cycles at stress range level $S r_{j}$ and $N_{j}$ is the number of cycles at constant stress range level $S r_{j}$ to cause fatigue failure, $k_{b}$ is the number of stress range blocks in the histogram over which summation is carried out. The process of evaluating the cumulative damage index has been repeated for all the simulated response samples and the average value is used to find the fatigue life $L_{f}$ given as

$$
L_{f}=\frac{1}{D_{I}}
$$

\section{Numerical examples and discussions}

The following parameters for the vehicle and the bridge [24, 25] have been selected for the illustration of the fatigue life evaluation:

Vehicle type-Two-axle (four degree-of-freedom); unsprung masses $\left(m_{1}=m_{2}\right): 2000 \mathrm{~kg}$, Sprung masses $(M s): 36000 \mathrm{~kg}$, Pitch moment of inertia $\left(I_{v}\right)$ : $144 \times 10^{3} \mathrm{kgm}^{2}$, Wheel base (a) $2.5 \mathrm{~m}$; Tyre stiffness $\left(k t_{1}=k t_{2}\right): 3.6 \times 10^{7} \mathrm{~N} / \mathrm{m}$, Suspension stiffness $\left(k s_{1}=k s_{2}\right): 0.9 \times 10^{7} \mathrm{~N} / \mathrm{m}$, Suspension damping: $\left(c s_{1}=c s_{2}\right), 7.2 \times 10^{4} \mathrm{~N} / \mathrm{ms}^{-1}$, Tyre damping: $\left(c t_{1}=c t_{2}\right): 0.5 \times 10^{2} \mathrm{~N} / \mathrm{ms}^{-1}$.

Bridge type: Number of spans:3, Length of the span: $l_{1}=l_{2}=l_{3}=20 \mathrm{~m}$, Moment of inertia of the cross section $(I): 1.82 \mathrm{~m}^{4}$, Mass per unit length: $m=2040 \mathrm{~kg} / \mathrm{m}$. Modulus of elasticity of concrete (M45): $33540 \mathrm{~N} / \mathrm{mm}^{2}$; Damping ratio $(\xi): 5 \%$ of the critical. Empirical fatigue strength equations [16]: $N_{f}\left(S_{r} / f_{c r}\right)^{23.49}=5.467$ where $f_{c r}$ is the flexural strength of the concrete, which is equal to $0.7 \sqrt{ } f_{c k}, f_{c k}$ being 28 days cube strength.

Pavement categories and roughness coefficients: Good, $\alpha_{s}=0.62 \times 10^{-6}$; Average, $\alpha_{s}=2.5 \times 10^{-6}$; Poor: $\alpha_{s}=12 \times 10^{-6}$. 


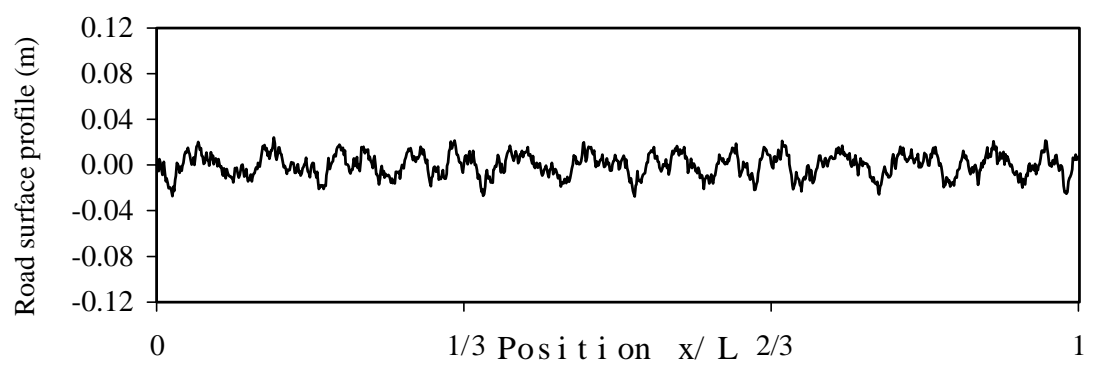

Fig. 6. A sample of bridge deck profile.

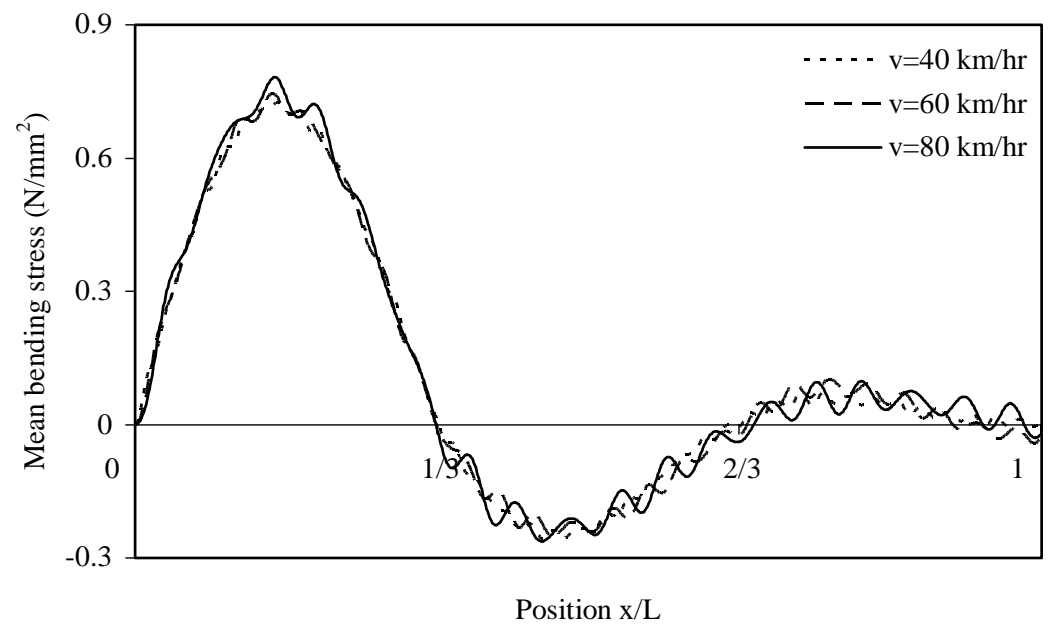

Fig. 7. Samples of flexural Stress History at middle of exterior span.

\subsection{Bridge deck roughness profile}

In the present study, the values of spectral roughness coefficient $\left(\alpha_{s}\right) 0.62 \times 10^{-6}, 2.5 \times 10^{-6}$ and $10 \times 10^{-6} \mathrm{~m}^{3} /(\mathrm{m} /$ cycle $)$ are used according to ISO specifications as the parameter for the classification of pavement into good, average and poor categories respectively. Twenty profiles of road roughness are generated for each type of road using the lower and upper limit of the spatial frequencies of the road profile as $\Omega_{l}=0.01 \mathrm{cycle} / \mathrm{m}$ and $\Omega_{u}=3.0$ cycle $/ \mathrm{m}$ respectively. In generating the random road surface roughness, random numbers $\varphi_{k}$ have been generated by using software tools MATLAB. The bridge length is taken as $20 \mathrm{~m}$ and deck profile heights are generated at discrete points along the span of the bridge. A sample of the vertical bridge deck surface profile for an average road is shown in Fig. 6 along dimensionless span.

\subsection{Flexural stress history}

The samples of flexural stress at the extreme fibre of the cross section at the middle of exterior, interior span and intermediate supports of the bridge have been obtained for different vehicle velocity. Slow and fast moving vehicles are covered in the study adopting operating speed range $20 \mathrm{~km} / \mathrm{h}-100 \mathrm{~km} / \mathrm{h}$. Three samples of bending stress at the middle of the exterior support are shown in Fig. 7 for various location of vehicle c.g along the span with vehicle speed $40 \mathrm{~km} / \mathrm{h}, 60 \mathrm{~km} / \mathrm{h}$ and $80 \mathrm{~km} / \mathrm{h}$. The vehicle c.g position measured from the left hand support has been normalized with the bridge span. The result indicates the presence of low amplitude high frequency component of flexural stress at the section. The peak magnitude of flexural stress is seen to occur when vehicle c.g is close to the section. The magnitude of stress increases with the increase of the vehicle speed. The percentage increase of the peak stress at the highest speed is about $15 \%-18 \%$ of that at the lowest vehicle speed considered in the study.

\subsection{Stress range histogram}

For flexural stress samples at mid span of the bridge obtained by numerical integration, the stress histogram 


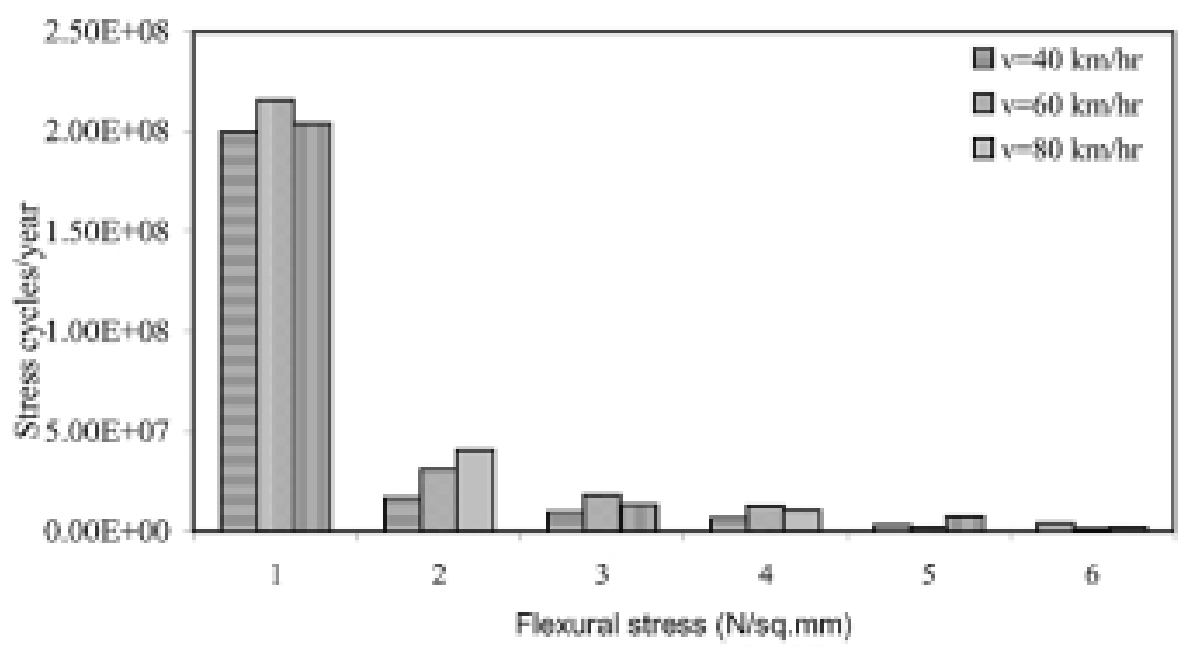

Fig. 8. Stress ranges versus Frequency (cycles/year) histogram for different vehicle speeds in "good" category pavement.

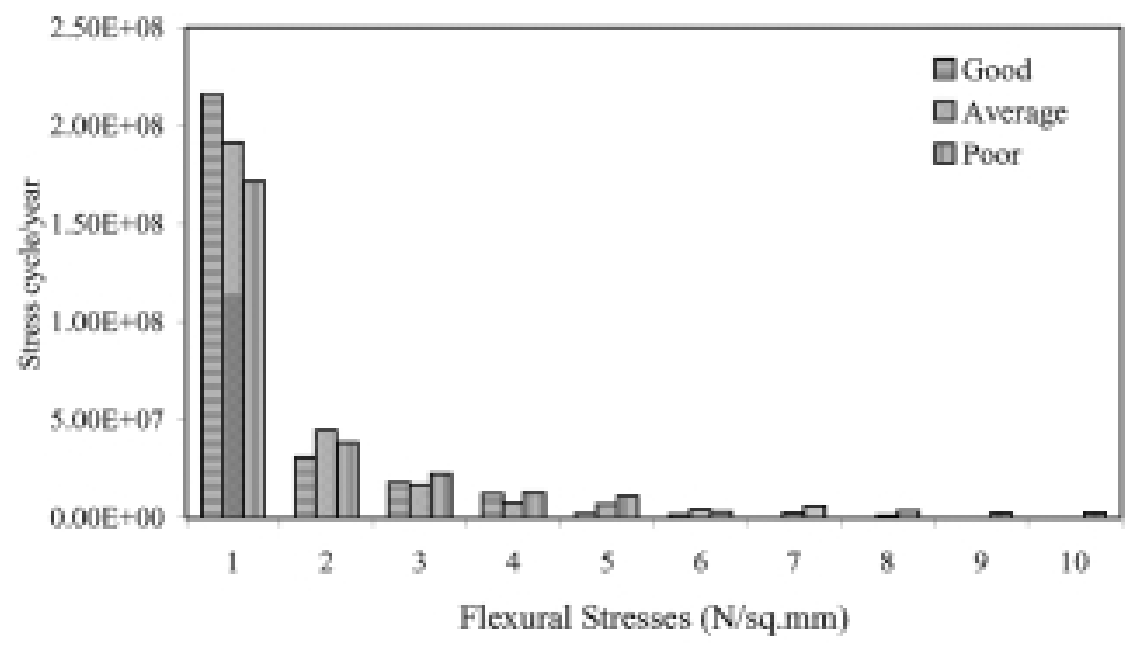

Fig. 9. Stress ranges versus Frequency (cycles/year) histogram for three different categories of pavement.

is prepared after synthesizing the time history by Rain flow counting method. It may be noted that the flexural stresses are calculated for the passage of single vehicle over the bridge. Assuming uniform traffic for all the days in a year, number of cycles obtained by Rainflow analysis is simply converted in to the annual cycles by using a constant multiplier (Average daily traffic $\times$ 365). The average daily traffic has been assumed as 1500 vehicles. Figure 8 shows a typical stress range vs. frequency (cycles/year) histogram with vehicle forward velocity $40 \mathrm{~km} / \mathrm{h}, 60 \mathrm{~km} / \mathrm{h}$ and $80 \mathrm{~km} / \mathrm{h}$ in good pavement condition. It is found that the bridge is subjected to maximum $2.2 \times 10^{8}$ cycles/year in the stress range of $0.5 \mathrm{~N} / \mathrm{mm}^{2}-1.5 \mathrm{~N} / \mathrm{mm}^{2}$ in the operating vehicle speed $60 \mathrm{~km} / \mathrm{h}$ to $80 \mathrm{~km} / \mathrm{h}$. In the higher stress range, the number of stress cycles experienced by the bridge, seems to decline. Figure 9 presents the stress range frequency histogram obtained for three stress history samples corresponding to three different categories of the pavement such as good, average and poor. The vehicle speed considered is $60 \mathrm{~km} / \mathrm{h}$. It reveals from the histogram analysis, that the maximum stress range $0.5 \mathrm{~N} / \mathrm{mm}^{2}-1.5 \mathrm{~N} / \mathrm{mm}^{2}$ generates around $1.7 \times 10^{8}$ to $2 \times 10^{8}$ cycles/year. The number of cycles of stress in higher stress range is found to be considerably low.

\subsection{Effect of different parameters on the fatigue life}

This section examines the effect of some of the important factors, which are believed to influence the fatigue life of the bridge. 


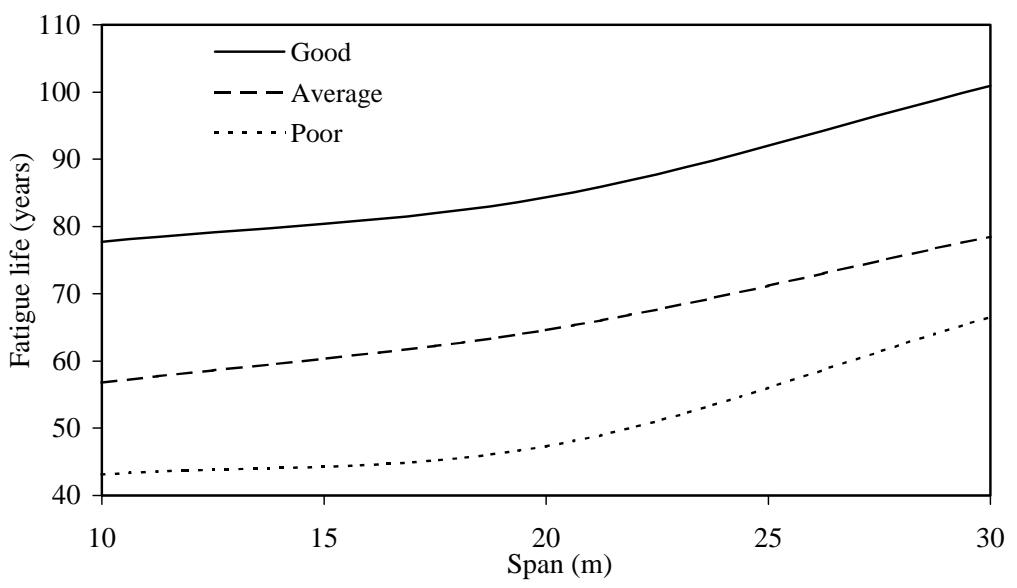

Fig. 10. Effect of individual span length on fatigue life.

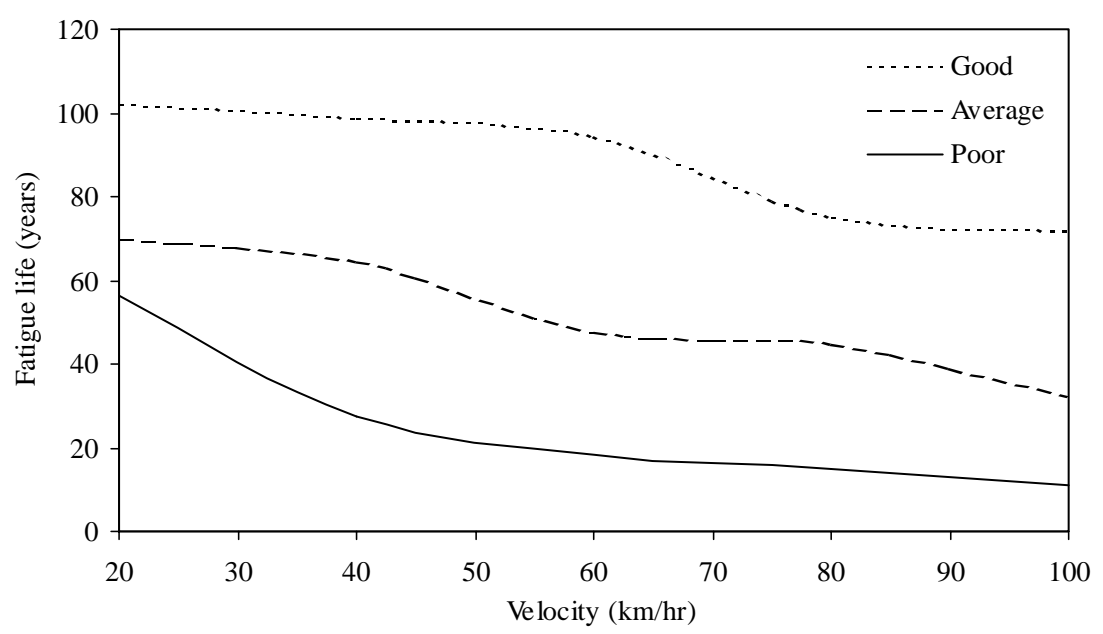

Fig. 11. Effect of vehicle speed on fatigue life.

\subsubsection{Effect of bridge span}

The continuous bridge with three equal spans, the individual span being in the range of $10 \mathrm{~m}$ to $30 \mathrm{~m}$ has been considered to examine the effect of the bridge span on fatigue life. The vehicle velocity is taken as $60 \mathrm{~km} / \mathrm{h}$. The results are graphically represented in Fig. 10 for three classes of bridge pavement viz. good, average and poor. It is seen that fatigue life of the bridge decreases as the pavement condition deteriorates. However, in each category of pavement, the bridge with longer span seems to have longer fatigue life. With the increase of the bridge span, natural frequencies of the bridge decrease in all the modes. The decrease in natural frequencies results in large amplitude stress cycles. However, the number of stress cycles in higher stress range considerably decreases yielding lower value of damage index. This effect may be attributed to the increase of fatigue life of the bridge. The results further reveals that the individual span in the range of $10 \mathrm{~m}-20 \mathrm{~m}$, the fatigue life is not very much effected by increasing the span.

\subsubsection{Effect of vehicle forward velocity}

Figure 11 shows the effect of forward velocity of the vehicle on the fatigue life of the continuous bridge. The vehicle constant velocity in the range $20 \mathrm{~km} / \mathrm{hr}-$ $100 \mathrm{~km} / \mathrm{hr}$ under different pavement conditions has been considered. A decrease in fatigue life of the girder was observed at high-speed vehicle movements along the bridge. The results indicate that the fatigue life of the bridge is reduced by increased velocity due to the increase of low amplitude high frequency component. In the good condition of the pavement, vehicle speed 


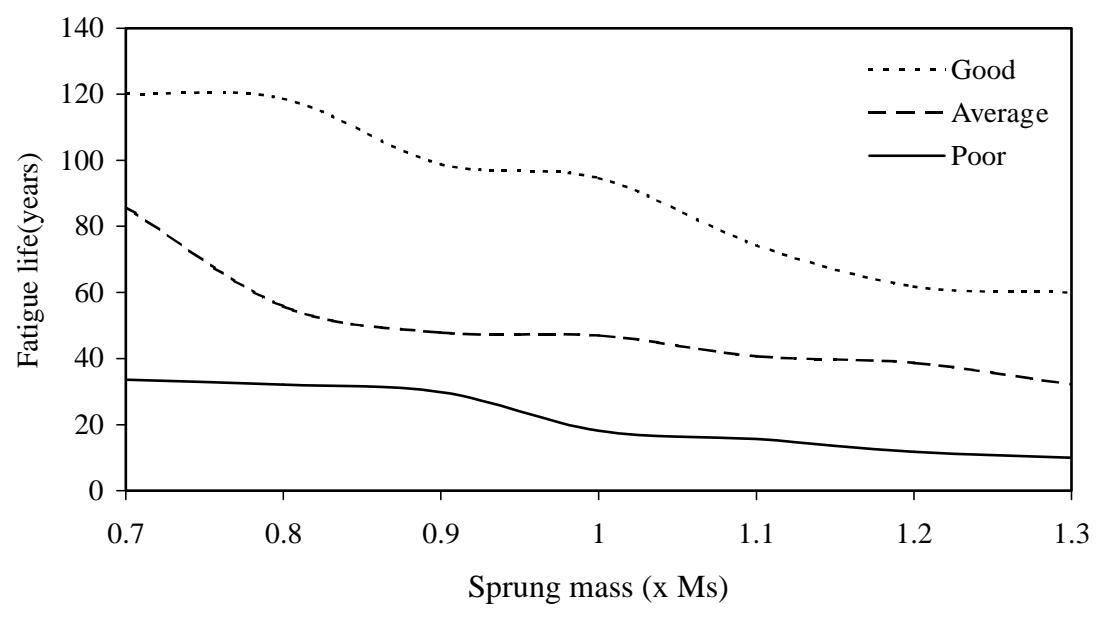

Fig. 12. Effect of vehicle sprung mass on fatigue life in different deck surface condition.

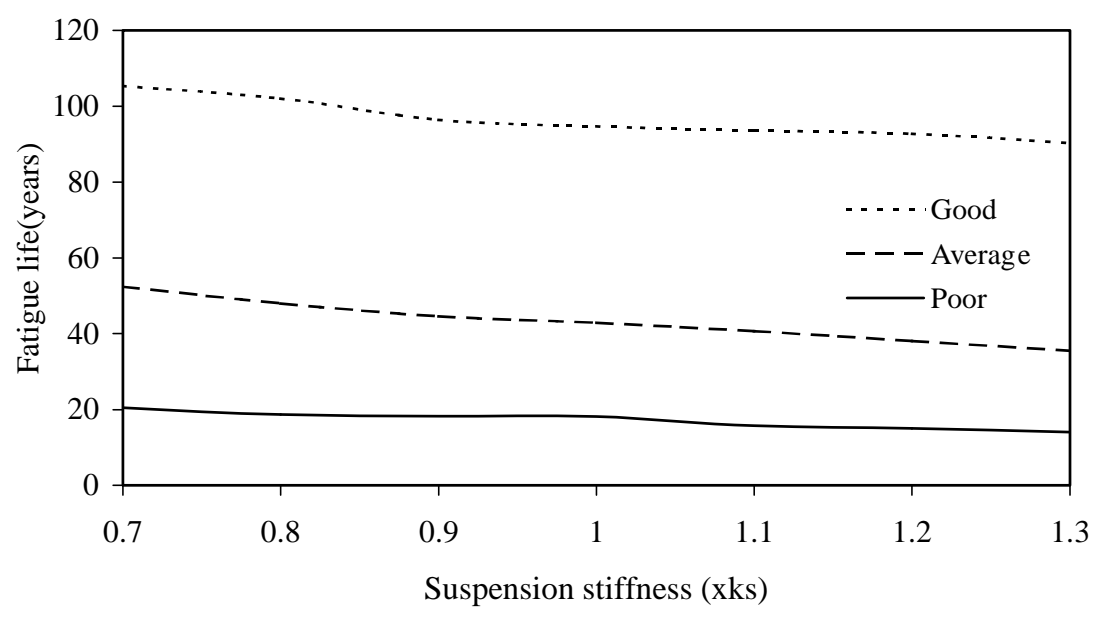

Fig. 13. Effect of suspension stiffness on fatigue life in different deck surface condition.

upto $60 \mathrm{~km} / \mathrm{h}$ does not cause much significant change in the fatigue life.

\subsubsection{Effect of vehicle sprung mass}

Figure 12 shows the effect of increased (or decreased) sprung mass on the fatigue life of the bridge. Different surface conditions (good, average and poor) have been considered in the study. The numerical experiment is performed with $\pm 30 \%$ variation of the sprung mass. The forward velocity of the vehicle is taken as $60 \mathrm{~km} / \mathrm{h}$. It is observed from the result that the fatigue life decreases with the increase of sprung mass irrespective of the condition of the bridge pavement. This may be due to increased deflection and flexural stress in the girder for the increase of vehicle load. However, the change is very insignificant for the variation of the sprung mass within $\pm 30 \%$ limit.

\subsubsection{Effect of suspension stiffness}

The dynamic tyre force transmitted on the bridge pavement greatly depends on the suspension stiffness. Figure 13 shows the variation of fatigue life of the bridge due to change of vehicle suspension stiffness considering different categories of pavement. A decrease in fatigue life can be observed with the increase of the suspension stiffness of the vehicle. The number of low amplitude stress cycles increases due to increase of natural frequency by use of stiffer spring in the vehicle suspension and the bridge pavement experiences more number of stress cycles than that produced by the vehicle with less stiffer spring. This may accelerate the fatigue damage of the bridge bringing down its fatigue life. However, the fatigue life of the bridge is not significantly altered due to change in the suspension stiffness. 


\section{Conclusions}

A systematic approach based on linear damage theory has been proposed for the calculation of the fatigue life of the bridge considering its dynamic interaction with the vehicle. The method requires the stress time history of the fatigue critical detail and fatigue strength parameters. The method has been applied to a multi span highway bridge after obtaining the flexural stress history by numerical simulation of the bridge-vehicle interaction dynamics. The fatigue strength parameters have been selected from the empirical relations appropriate to the material type from published reports. A study has been conducted to examine the effect of some of the important parameters on the fatigue life. The following conclusions can be drawn from the numerical experiment with the selected parameters and with limited number of stress samples

(1) The fatigue life of the bridge based on flexural stress generated by moving vehicles is not affected very much by the increase of individual span up to $20 \mathrm{~m}$ in a continuous bridge. Beyond $20 \mathrm{~m}$ span, the fatigue life increases with the increase of the individual span of the continuous bridge girder.

(2) The vehicles moving with higher velocity increase the stress magnitude, thereby enhancing the fatigue damage, which leads to reduced fatigue life of the bridge.

(3) The vehicles plying with larger payload over the bridge enhance the fatigue damage reducing the life of the bridge.

(4) The vehicle suspension stiffness has insignificant effect on the bridge fatigue life although some reduction in fatigue life occurs due to high value of the suspension stiffness.

(5) The condition of the bridge pavement is found to be a key parameter affecting the fatigue life of the bridge. The deteriorated bridge pavement needs to be repaired to improve the performance of the bridge under fatigue.

\section{References}

[1] J.A. Bennantine, J.J. Commer and J.L. Handrock, Fundamentals of Metal Fatigue Analysis, Prentice Hall, Englewood Cliffs, New Jersy, 1990.

[2] M.A. Miner, Cumulative damage in fatigue, Journal of Applied Mechanics, ASME 67 (1945), 159-164.

[3] Guide specifications for fatigue of steel bridges, American
Association of State Highway and Transportation Officials (AASHTO), Washington, DC, 1989.

[4] BS:5400: Part 10: "Steel, concrete and composite BridgesPart10: Code of practice for fatigue", British Standards Institution, 1980.

[5] Bridge Rules (in SI units), Ministry of Railways, Govt. of India., Revised 1964.

[6] IRC-22: Standard specifications and code of road bridges, Section-VI, Composite construction, 1986.

[7] N.E. Dowling, Fatigue failure predictions for complicated strain histories, Journal of Materials 7 (1972), 71-87.

[8] P.H. Wirsching and M.C. Light, Fatigue under wide band random process, Journal of Structural Engineering, ASCE 106 (1980), 1593-1607.

[9] L.D. Lutes, M. Corazao, S.J. Hu and J. Zimmerman, Stochastic fatigue damage accumulation, Journal of Structural Engineering 110 (1984), 2585-2601.

[10] L.D. Lues and C.E. Larsen, Improved spectral method for variable amplitude fatigue prediction, Journal of Structural Engineering, ASCE 116 (1990), 1149-1164.

[11] P. Paris and F. Erdogen, A critical analysis of crack growth propagation laws, Journal of Basic Engineering, ASME $\mathbf{8 5}$ (1963), 528-534.

[12] Z. Zhao, A. Halder and Jr F.L. Breen, Fatigue reliability evaluation of steel bridges, Journal of Structural Engineering, ASCE 120 (1994), 1608-1622.

[13] G. Ravi and R. Ranganathan, Fatigue crack reliability of riveted bridge, International Journal of Structures 14 (1994), 103-108.

[14] L. Fryba, Dynamics of railway bridges, Thomas Telford, 1996.

[15] Illinois Department of Transport, Bureau of Materials and Physical research, Accurate and rapid determination of fatigue damage in bridge superstructures, Physical research report no. 106.

[16] B.H. Oh, Fatigue analysis of plain concrete in flexure, Journal of Structural Engineering, ASCE 112 (1986), 273-286.

[17] P.C. Perdikaris, S.R. Beim and S.N. Bousias, Slab continuity on ultimate and fatigue strength of reinforced concrete bridge deck models, Journal of Structural Engineering, ASCE 86 (1989), 483-491.

[18] J. Mohammadi, S.A. Guralnick and R. Polepeddi, Bridge fatigue life estimation from field data, Practice Periodical on Structural Design and Construction ASCE 3 (1998), 128-133.

[19] M. Schlaffi and E. Bruhwiler, Fatigue of existing reinforced concrete bridge deck slabs, Engineering Structures 20 (1998), 991-998.

[20] American Society for Metals, Atlas of fatigue curves, H.E. Boyer, ed., 1986.

[21] E.S. Hwang and A.S. Nowak, Simulation of dynamic load for bridges, Journal of Structural Engineering ASCE 117 (1991), 1413-1434.

[22] L. Meirovitch, Elements of vibration analysis, Mc. Graw Hill, 1986.

[23] K.J. Bathe and E.L. Wilson, Numerical methods in finite element analysis, Prentice-Hall, Inc., Englewood Cliffs, NJ, USA, 1987.

[24] M.F. Green and D. Cebon, Dynamic response of highway bridges to heavy loads: theory and experimental validation, Journal of Sound and Vibration 170 (1993), 51-78.

[25] Y.A. Dugush and M. Eisenberger, Vibration of non-uniform continuous beams under moving loads, Journal of Sound and Vibration 254 (2002), 911-926. 


\section{Appendix-I}

Nomenclatures

$A \quad$ Peak magnitude

$A_{n r} \quad$ Integration constants

a Wheel base

$[C] \quad$ System damping matrix

$c \quad$ Viscous damping per unit length

$c_{s 1}, c_{s 2}$ Front and rear suspension damping respectively

$c_{t 1}, c_{t 2} \quad$ Front and rear tire damping respectively

$D_{I} \quad$ Cumulative damage index

$E \quad$ Young's Modulus of Elasticity

$\{F\} \quad$ Force vector

$f \quad$ Distributed load

$h \quad$ Bridge deck profile height

I Moment of inertia of the bridge cross section

$I_{v} \quad$ Mass moment of inertia of the vehicle

$[K] \quad$ System stiffness matrix

$K \quad$ Parameter of $S-N$ curve

$k_{s 1}, k_{s 2} \quad$ Stiffness of the front and rear suspension respectively

$k_{t 1}, k_{t 2}$ Stiffness of the front and rear tire respectively

$L \quad$ Total span of the bridge

$L_{f} \quad$ Fatigue life

$l_{a 1}, l_{a 2} \quad$ Distance of front and rear wheel respectively from vehicle c.g

$l_{r} \quad$ rth span of the continuous bridge

$[M] \quad$ System mass matrix

$M_{s} \quad$ Sprung mass

$m \quad$ Parameter of $S-N$ curve

$m_{1}, m_{2} \quad$ Front and rear unsprung mass respectively

$m_{b} \quad$ Mass of the bridge per unit length

$N \quad$ Number of terms of a series

$n_{b} \quad$ Number of bending modes

$N_{f} \quad$ Number of stress cycles to failure

$n_{j} \quad$ Number of stress cycles at particular stress range

$Q \quad$ Generalized force

$S_{r} \quad$ Stress range

$t \quad$ Time instant

$\{U\} \quad$ Response vector

$V \quad$ Vehicle forward velocity

$x \quad$ Distance

$y \quad$ Vertical displacement of the bridge

$Z \quad$ Displacement of sprung mass

$Z_{1}, Z_{2} \quad$ Displacement of front and rear unsprung masses respectively
Roughness coeffecient

Frequency parameter per unit length

Modal damping ratio

Generalized coordinate

Circular frequency $(\mathrm{rad} / \mathrm{sec})$

Spatial frequency $(\mathrm{rad} / \mathrm{m})$

Phase angle

Pitch rotation

Power spectral density

$\Delta D \quad$ Incremental damage

\section{Appendix-II}

The mode shape function for multi-span continuous beam is given by

$$
\begin{aligned}
\phi_{n r}(x) & \left\{\begin{array}{c}
\sin \left(\beta_{n r} x_{1}\right)-\frac{\sin \left(\beta_{n r} l\right)}{\sinh \left(\beta_{n r} l\right)} \sinh \left(\beta_{n r} x_{1}\right) \\
r=1 \\
P_{r} M_{r}\left(x_{r}\right)+Q_{r} N_{r}\left(x_{r}\right) \\
r=2,3, \ldots, N
\end{array}\right. \\
P_{r}= & \left\{\left[\cosh \left(\beta_{n r} l\right)-\cos \left(\beta_{n r} l\right)\right]\right. \\
& {\left[\sin \left(\beta_{n r} l\right) \sinh \left(\beta_{n r} l\right)\right] } \\
& -\sin \left(\beta_{n r} l\right)\left[\sinh \left(\beta_{n r} l\right) \cos \left(\beta_{n r} l\right)\right. \\
& \left.\left.-\sin \left(\beta_{n r} l\right) \cosh \left(\beta_{n r} l\right)\right]\right\} / \\
& \left\{\operatorname { s i n h } ( \beta _ { n r } l ) \left(\left[\cos \left(\beta_{n r} l\right)-\cosh \left(\beta_{n r} l\right)\right]\right.\right. \\
& {\left.\left.\left[\sinh \left(\beta_{n r} l\right)-\sin \left(\beta_{n r} l\right)\right]\right)\right\} } \\
Q_{r}= & \left\{\left[\cos \left(\beta_{n r} l\right)-\cosh \left(\beta_{n r} l\right)\right]\right. \\
& {\left[\sin \left(\beta_{n r} l\right) \sinh \left(\beta_{n r} l\right)\right] } \\
& +\sinh \left(\beta_{n r} l\right)\left[\sinh \left(\beta_{n r} l\right) \cos \left(\beta_{n r} l\right)\right. \\
& \left.\left.-\sin \left(\beta_{n r} l\right) \cosh \left(\beta_{n r} l\right)\right]\right\} / \\
\{ & \sinh \left(\beta_{n r} l\right)\left(\left[\cos \left(\beta_{n r} l\right)-\cosh \left(\beta_{n r} l\right)\right]\right. \\
& {\left.\left.\left[\sinh \left(\beta_{n r} l\right)-\sin \left(\beta_{n r} l\right)\right]\right)\right\} }
\end{aligned}
$$

$M_{r}\left(x_{r}\right)$

$=\left\{\left[\cos \left(\beta_{n r} l\right)-\cosh \left(\beta_{n r} l\right)\right] \sinh \left(\beta_{n r} x\right)\right.$

$\left.+\sinh \left(\beta_{n r} l\right)\left[\cosh \left(\beta_{n r} x\right)-\cos \left(\beta_{n r} x\right)\right]\right\}$

$N_{r}\left(x_{r}\right)$

$=\left\{\left[\cos \left(\beta_{n r} l\right)-\cosh \left(\beta_{n r} l\right)\right] \sin \left(\beta_{n r} x\right)\right.$

$\left.+\sin \left(\beta_{n r} l\right)\left[\cosh \left(\beta_{n r} x\right)-\cos \left(\beta_{n r} x\right)\right]\right\}$ 

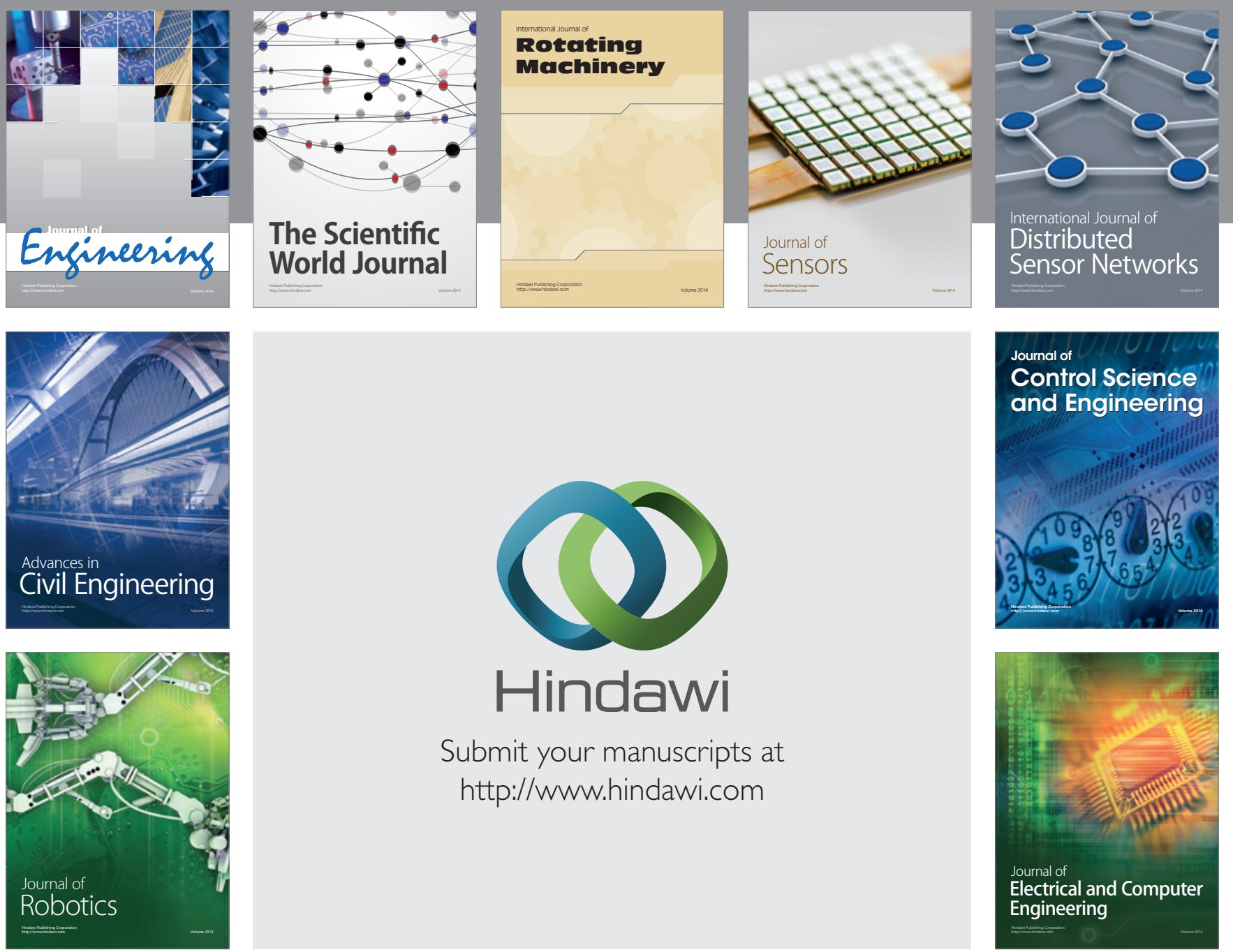

Submit your manuscripts at

http://www.hindawi.com
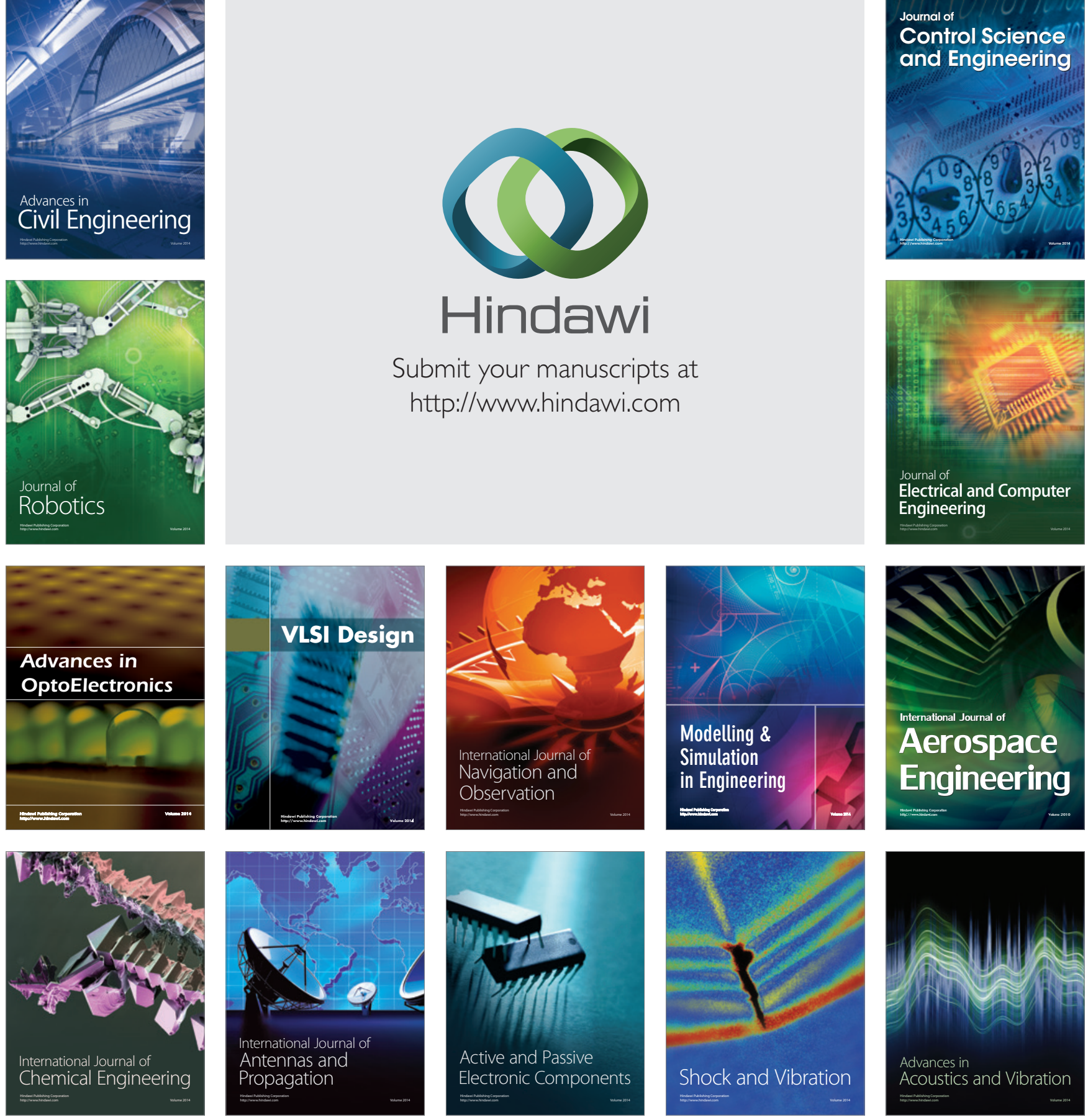